\title{
Computer aided tool design for micro-ECM
}

\section{Pratik R. Shah* and S.S. Pande}

Computer Aided Manufacturing Laboratory, Department of Mechanical Engineering, Indian Institute of Technology, Bombay, Powai, Mumbai, 400076, India

Email: pratik91006@gmail.com

Email: s.s.pande@iitb.ac.in

*Corresponding author

\begin{abstract}
This paper reports the development of a computer aided system for micro-ECM process to design tools to produce accurate internal features on workpiece. Mathematical model has been developed to compute the inter-electrode gap (IEG) for chosen shape of tool and process conditions. Axi-symmetric tools of different profiles such as cylindrical, conical, hemispherical have been analysed to predict the shapes of work cavities. Model is validated with the reported results and some experiments conducted by us on typical tool shapes. Parametric studies have been carried out to study influence of various process variables on the accuracy of cavity shapes. Based on these studies, guidelines for improving profile accuracy in micro-ECM have been suggested.
\end{abstract}

Keywords: micro-ECM; computer aided design system; inter-electrode gap; IEG; tool design; process model; parametric studies.

Reference to this paper should be made as follows: Shah, P.R. and Pande, S.S. (2020) 'Computer aided tool design for micro-ECM', Int. J. Precision Technology, Vol. 9, No. 1, pp.1-20.

Biographical notes: Pratik R. Shah completed his MTech in Mechanical from the IIT Bombay in Manfacturing in June 2016. He is currently working from the General Motors Technical Center India, Bangalore since July 2016. During his Master's duration, he worked on tool design for micro-ECM (non-traditional machining).

S.S. Pande is a Professor form the Department of Mechanical Engineering, IIT Bombay. His primary focus on research has been on intelligent product design and manufacturing and internet-based collaborative CAD/CAM. Specific areas are artificial intelligence techniques - neural networks and genetic algorithms, geometric reasoning of CAD models - feature extraction, feature-based modelling, intelligent product modelling - concept design, sketch-based modelling, intelligent $\mathrm{CNC}$ machining - multi-axis $\mathrm{CNC}$, feature-based $\mathrm{CNC}$ machining, efficient algorithms for rapid prototyping, computer assisted process planning, process modelling and optimisation of precision machining processes.

This paper is a revised and expanded version of a paper entitled 'Computer aided tool design for micro-ECM' presented at 6th International and 27th All India Manufacturing Technology, Design and Research Conference AIMTDR2016, College of Engineering Pune, India, 16-18 December, 2016. 


\section{Introduction}

Requirement of miniature components made from high strength materials such as titanium alloys, carbides and tool steel is increasing in automotive, aerospace, medical devices and electronics industries. They are difficult to machine using traditional machining processes due to problems like high tool wear, work shape distortion, heat affected zones (HAZs), etc. which, in turn, reduce the life of components. Several methods like laser drilling, electric discharge machining (EDM) and electrochemical machining (ECM) are suggested to machine micro features like holes. Quality of hole produced by laser drilling is affected due to formation of HAZ and recast layer (iaRajurkar et al., 2013). Major problem associated with EDM is high tool wear along with the formation of HAZ and recast layer being a thermal process. In comparison, electrochemical micromachining (EMM) is very promising as it offers advantages such as no tool wear, better precision and machining capability for a wide range of materials (Bhattacharyya et al., 2002).

ECM is an anodic dissolution process working on the principle of electrolysis. Workpiece and pre-shaped tool are respectively made anode and cathode (constant D.C. voltage) and electrolyte is continuously circulated through inter-electrode gap (IEG). Due to localised dissolution of anode, shape of the workpiece is approximately negative mirror image of the tool. Micro-ECM uses smaller machining gap and low voltage to guarantee uniformity of machining gap and high shape reproduction accuracy for miniature parts.

Literature reports that most of the work on micro-ECM is focused on the experimental front to study the effect of process variables for improving the form (profile) accuracy of work piece produced. Few attempts have been directed to develop analytical models to study the electro-chemical phenomena for the prediction of MRR. Jo et al. (2009) generated complex internal microstructures by controlling pulse conditions and machining time. Ghoshal and Bhattacharyya (2015) used various shapes of tools such as straight, conical and reversed tapered to reduce hole taper angle. Mithu et al. (2012) produced numerous micro-tools to investigate effect of tool diameter, tool length and applied frequency on shape of micro-holes. Ahn et al. (2004) developed two step process for taper reduction in cylindrical micro-holes. Kim et al. (2005) used disc-type electrodes to reduce taper angle whereas $\mathrm{Mi}$ et al. (2015) used controlling conductive area ratio along tool electrode to generate holes with complex internal features. Mathew and Sundaram (2012) developed mathematical model to predict diameter of the tool produced by pulsed micro-ECM process. Kozak et al. (2008) modelled pulsed micro-ECM process considering unsteady behaviour of double layer phenomenon.

Despite these analytical and experimental studies, no clear guidelines have been reported for the design of micro-ECM tools for improving the profile accuracy of internal features (holes) produced on parts. The present research work is an attempt in this direction. 


\section{Process modelling and simulation of micro-ECM}

\subsection{Overview}

The objective herein is to develop computer aided system for the design of tool for micro-ECM to achieve required accurate shape of workpiece. A mathematical model is developed which predicts work shape for the given shape of the tool and process conditions in a forward analysis mode. Tool profile along with process parameters is given as input to the model. The model computes IEG at each point on the tool profile analysing the electrolysis phenomena. Work profile is predicted based on the calculation of IEG at each point. In the present work, axi-symmetric shape of the tool is considered. Overall flow of the process model is described below.

\subsection{Development and Implementation of process model}

Figures 1(a) and 1(b) shows the initial and final position of cylindrical tool and the taper shape formed on the workpiece. To explain the model, a cylindrical tool shape is considered. Initially, required shape of workpiece (exact negative of tool shape) is given as input to the model. Boundary of the workpiece is discretised into number of nodes (Figure 2) depending on feed rate and pulse time such that distance between two nodes equals the distance travelled by the tool in one pulse.

Figure 1 Tool and workpiece, (a) initial (b) final

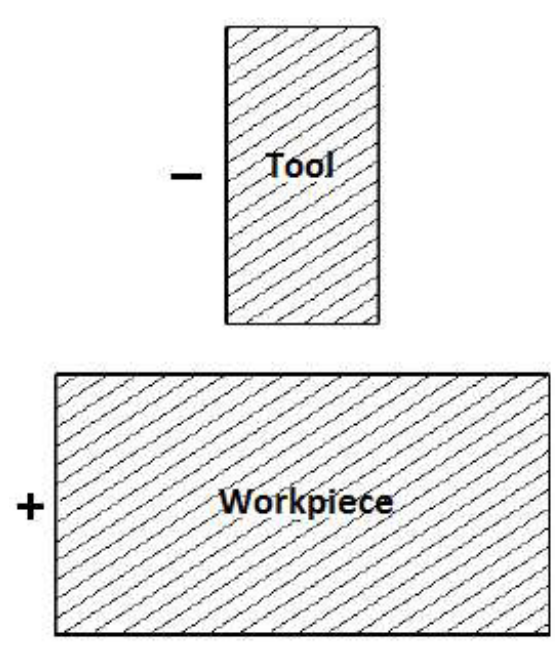

(a)

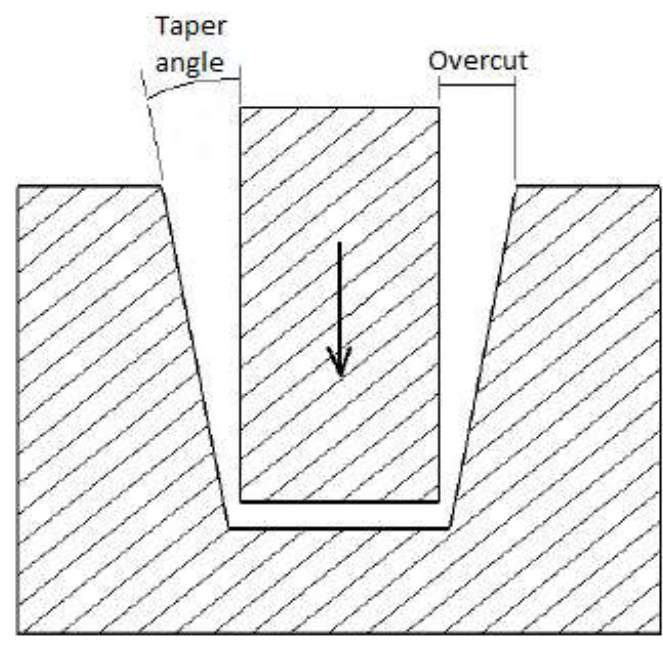

(b)

The model considers quasi-static movement of the tool into the workpiece corresponding to each time pulse. Let,

$d_{h}$ depth of hole

$d_{t}$ diameter of tool

$U$ applied voltage 
$K$ electrolyte conductivity

$K_{v}$ coefficient of electrochemical machinability

$E$ double layer over-potential

$V_{f}$ feed rate

$t_{p}$ pulse-ON time

$T_{p}$ pulse time.

The chosen parameters are considered constant during electrolysis (Shah, 2015).

Distance between two nodes is the distance travelled by tool in one pulse time. It is given by

$$
1=V_{f} \times T_{p}
$$

Number of nodes on the work boundary are calculated by

$$
n=\frac{d_{h}}{V_{f} \times t_{p}}
$$

To compute work cavity profile due to micro-ECM, total radial displacement at each node is calculated. Final work profile is obtained by calculating total radial displacement at each node. Figure 2 shows nodal radial displacement for some typical nodes as the tool progresses axially into the workpiece.

Figure 2 Nodal displacement with tool progression (see online version for colours)

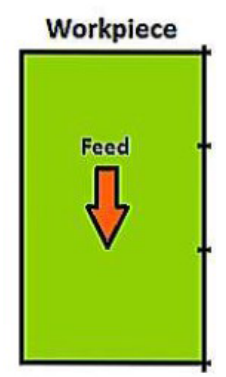

(a)

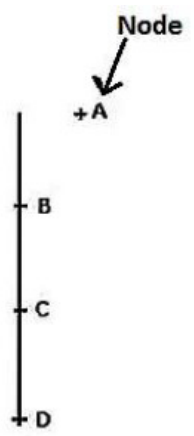

(b)

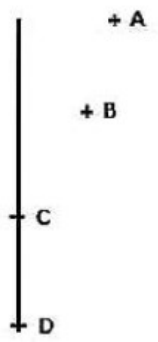

(c)

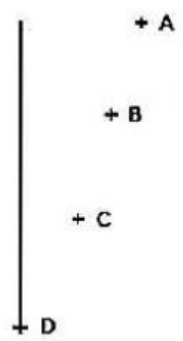

(d)

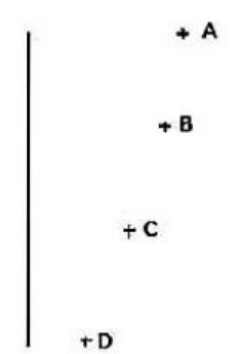

(e)

When tool is in contact with node at the entry of hole (i.e., node A, Figure 2), material at node A [Figure 2(a)] gets radially dissolved due to machining. As a result, node A gets displaced radially from the axis of tool by a distance equal to the initial equilibrium gap. It is given by $U-E$.

$$
S_{f}=K K_{v} \frac{U-E}{V_{f}}
$$

At this point of time, other nodes like B, C, D are not in contact with the tool and no displacement takes place at these nodes. 
As tool progresses to node B, material at node B [Figure 2(c)] gets radially dissolved similar to node A in the previous quasi-steady cycle. As a result, node B gets displaced radially from the axis of tool by a distance equal to the initial equilibrium gap given by equation (3). At this position of the tool, nodes C and D are not in electrochemical contact with the tool resulting in no displacement. But node $\mathrm{A}$ is in electrochemical contact with vertical boundary of the tool resulting in additional displacement. The radial displacement of node due to dissolution is based on equilibrium gap [Figure 2(c)]. It can be noted that additional displacement occurs now at node $\mathrm{A}$. This incremental displacement of A in second cycle would be different (less) than the one occurred in the previous cycle.

For ECM process, dissolution of material at particular point on the workpiece is proportional to current density at that point. Node A is already displaced in the previous time frame. Current density on the work surface reduces with increase in gap, thus reducing the additional nodal displacement at node $\mathrm{A}$ in step 2.

As the gap between tool and workpiece is very small, current density on the work surface is linearly approximated as under (Kozak et al., 1998).

$$
i_{a}=K \frac{U-E}{S_{f}}
$$

The radial displacement of the boundary of work surface at the point is proportional to the normal current density that point. It is given by (Prentice and Tobias, 1982)

$$
\Delta H n=\frac{A I}{Z F \rho} t_{p}
$$

where

$A$ atomic weight of material

I current

$Z \quad$ valency of material

$F$ faradays constant $(96,500$ coulomb)

$\rho$ density of material.

Therefore, when tool is in contact with node $\mathrm{B}$, total displacement of node $\mathrm{A}$ is given by

$$
S_{f}=S_{f}+\Delta H_{n}
$$

Same process continues for all nodes on the workpiece surface as tool progresses (fed) axially as per time steps (pulse).

Total time of contact of a particular node with the tool is calculated and for that time, IEG is modified continuously by using equations (5) and (6).

The model considers quasi-static operation of the tool and computes the incremental radial displacement of each node as the tool progress into the work.

Using this logic, equation for time of contact at each node is computed as under.

$$
t_{\text {contact }}=\frac{d_{h}-N l}{V_{f}}
$$


where

$N$ current node number.

Therefore, to summarise, time of contact for each node is calculated and for that time, the node is displaced radially by taking into consideration modified IEG and the current density variation to find out total displacement at each node. All the displaced nodes on workpiece are joined together to obtain the final work profile likely to be produced.

Figure 3 discusses flowchart for the model.

Figure 3 Flowchart of the model

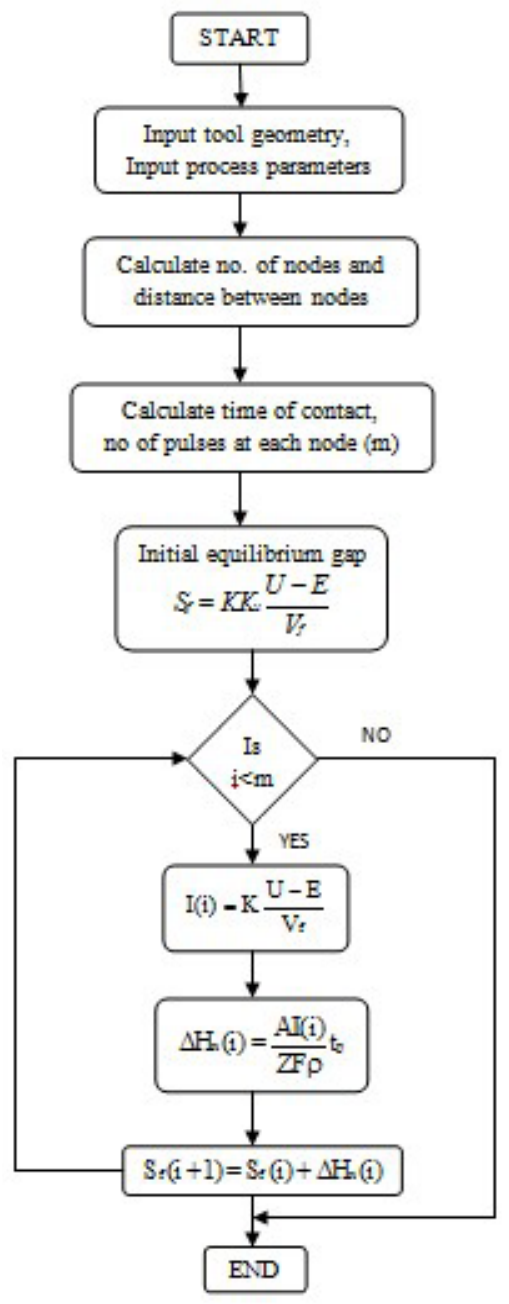

\subsection{Model validation and parametric studies}

The above model was implemented in MATLAB to get work profile for a given shape of the tool. Extensive numerical simulations were carried out to study how work profile 
varies with different parameters (Shah, 2015). Tools of various shapes such as cylindrical, conical and hemispherical were chosen for study.

Cylindrical tool is considered initially for the detailed study reported. Table 1 shows set of parameters used for parametric studies. Effect of each parameter is measured in terms of taper angle and MRR (MRR = volume/time).

Since in this work, the time of machining is kept constant, volume is material is chosen to represent MRR. MRR trends will be similar to those of volume of material removed.

Figure 4(a) shows 2D work profile generated by the model for $0.2 \mathrm{~mm}$ diameter tool (Table 1). 3D representation of the in-tool and the predicted hole is shown by Figure 4(b). Extensive parametric studies have been conducted using the model. These are reported in this section to follow.

Figure 4 (1) 2D cross-section of tool and work profile for cylindrical tool (b) 3D tool (centre) and work profile (outside) (see online version for colours)

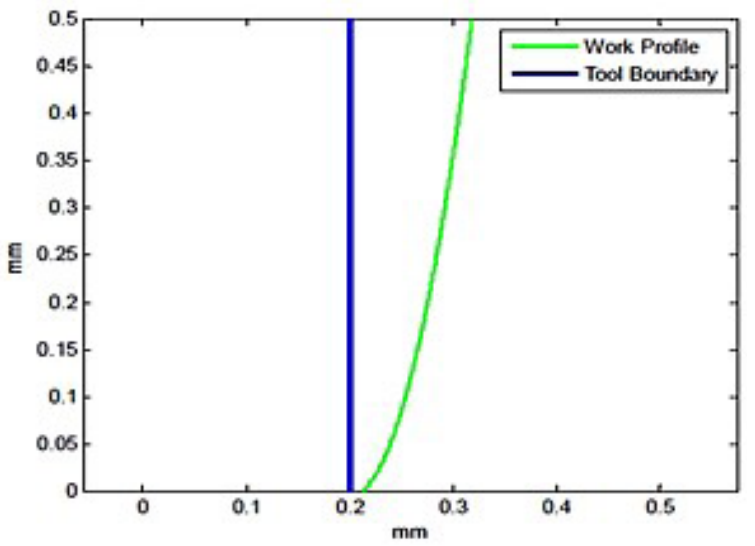

(a)

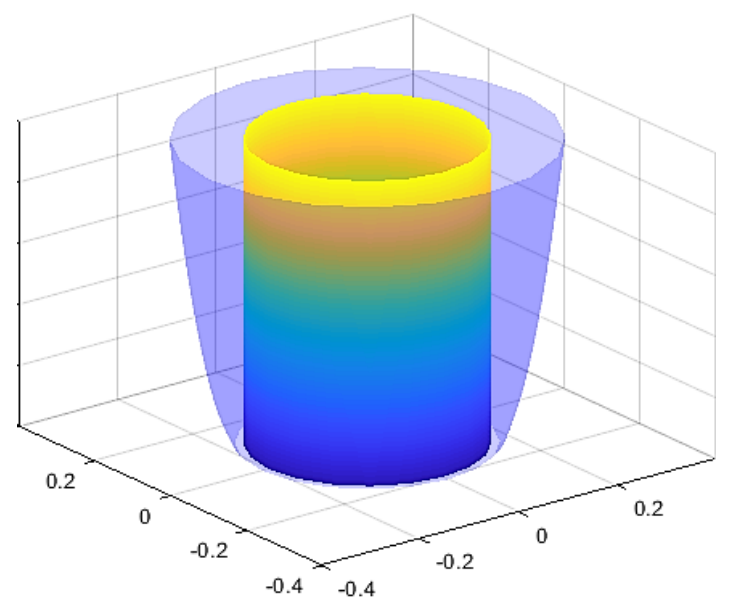

(b) 
Table 1 Parameters used for study

\begin{tabular}{lc}
\hline Parameters & Value \\
\hline Depth of hole to be machined & $0.5 \mathrm{~mm}$ \\
Diameter of tool (cylindrical) & $0.2 \mathrm{~mm}$ \\
Applied voltage & $5 \mathrm{~V}$ \\
Electrical conductivity of electrolyte [K] (Shin et al., 2008) & $0.04 \mathrm{mS} / \mathrm{cm}$ \\
Machinability coefficient [K $\mathrm{K}_{\mathrm{v}}$ (Prentice and Tobias, 1982) & $0.2 \mathrm{~mm} / \mathrm{min}$ \\
Feed rate & $0.5 \mu \mathrm{m} / \mathrm{s}$ \\
Pulse-ON time & $200 \mathrm{~ns}$ \\
Pulse time & $2 \mu \mathrm{s}$ \\
\hline
\end{tabular}

\subsubsection{Effect of applied voltage}

Applied voltage is varied keeping all other parameters constant and variation of taper angle, MRR and overcut is observed as shown in Table 2.

Table 2 Variation of geometric parameters with applied voltage

\begin{tabular}{lccc}
\hline Applied voltage $(V)$ & Taper (degrees) & Volume $\left(\mathrm{mm}^{3}\right)$ & Overcut $(\mathrm{mm})$ \\
\hline 2 & 2.2416 & 0.0099 & 0.0249 \\
4 & 2.9005 & 0.0156 & 0.036 \\
6 & 3.3234 & 0.0207 & 0.045 \\
8 & 3.6324 & 0.0257 & 0.0531 \\
\hline
\end{tabular}

Taper angle is defined as the angle formed by the vertical boundary of the work profile produced with respect to axis of the tool, whereas overcut is defined as radial distance between tool boundary and entry of the work profile produced.

Figure 5(a) shows that overcut increases monotonically with increase in applied voltage. This is because as applied voltage increases, more energy is available for material dissolution resulting in increase in taper angle and hence overcut. Supply of dissolution energy increases with increase in voltage resulting in expected increase in MRR as shown in Figure 5(b). The trend of model results is similar to the experimental results by Shin et al. (2008).

Figure 5 (a) Overcut vs. applied voltage (b) MRR vs. applied voltage (see online version for colours)

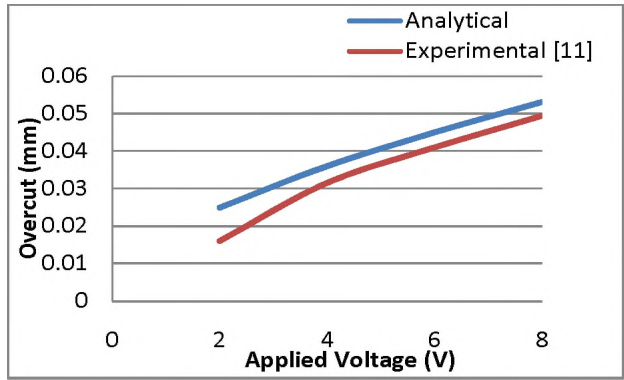

(a)

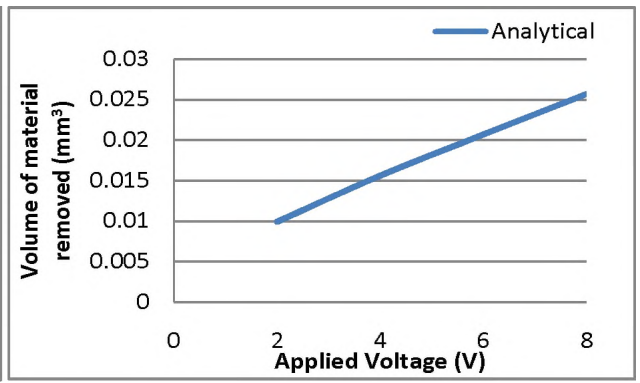

(b) 


\subsubsection{Effect of feed rate}

Feed rate is varied keeping all other parameters constant and variation of taper angle, MRR and overcut is observed as shown in Table 3.

Table 3 Variation of geometric parameters with feed rate

\begin{tabular}{lccc}
\hline Feed rate $(\mu \mathrm{m} / \mathrm{s})$ & Taper $($ degrees $)$ & Volume $\left(\mathrm{mm}^{3}\right)$ & Overcut $(\mathrm{mm})$ \\
\hline 0.5 & 11.8697 & 0.0497 & 0.1184 \\
1 & 8.7471 & 0.0323 & 0.0836 \\
2 & 6.3823 & 0.0216 & 0.0593 \\
5 & 4.2886 & 0.0134 & 0.0388 \\
\hline
\end{tabular}

Figure 6(a) shows that overcut decreases with increase in feed rate. This is because as feed rate increases, time available for material removal reduces, resulting in reduction in taper angle and hence overcut as well as MRR [Figure 6(b)].

Figure 6 (a) Overcut vs. feed rate (b) MRR vs. feed rate (see online version for colours)

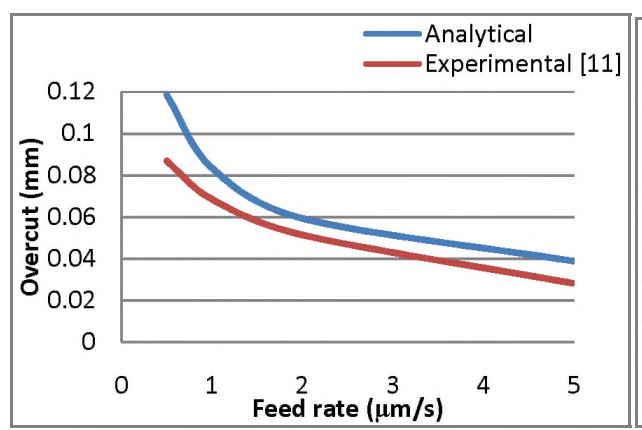

(a)

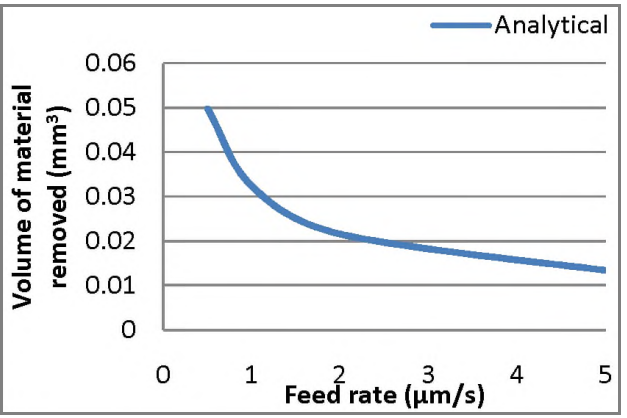

(b)

\subsubsection{Effect of pulse-ON time}

Pulse-ON time is varied keeping all other parameters constant and variation of taper angle, MRR and overcut is observed (Table 4).

Table 4 Variation of geometric parameters with pulse-ON time

\begin{tabular}{lccc}
\hline Pulse-ON time $T_{\text {ON }}(\mathrm{ns})$ & Theta (degrees) & Volume $\left(\mathrm{mm}^{3}\right)$ & Overcut $(\mathrm{mm})$ \\
\hline 100 & 8.073 & 0.0351 & 0.0843 \\
150 & 10.1411 & 0.0428 & 0.1028 \\
200 & 11.8697 & 0.0497 & 0.1184 \\
250 & 13.3774 & 0.0559 & 0.1322 \\
300 & 14.7259 & 0.0617 & 0.1447 \\
\hline
\end{tabular}

Figure 7(a) shows that overcut increases with increase in pulse-ON time. This is because as pulse-ON time increases, duty cycle increases, i.e., more percentage of pulsed cycle is used for material removal. Therefore, more time is available for material removal resulting in increase in taper angle and hence overcut as well as MRR [Figure 7(b)]. 
Figure 7 (a) Overcut vs. pulse-ON time (b) MRR vs. pulse-on time (see online version for colours)

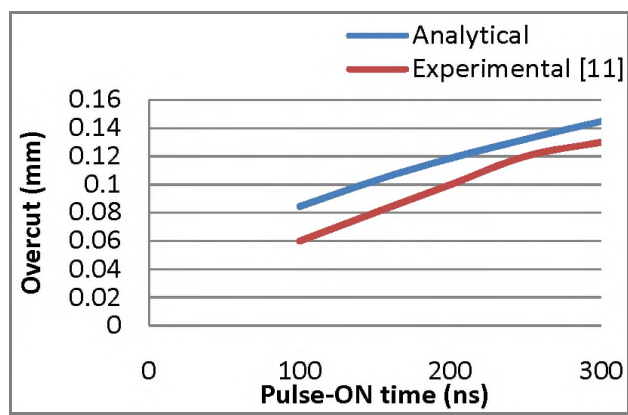

(a)

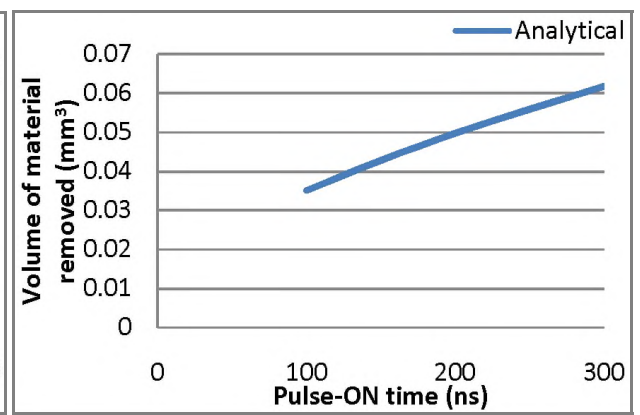

(b)

\subsubsection{Effect of pulse-OFF time}

Pulse-OFF time is varied keeping all other parameters constant to study the variation of taper angle, MRR and overcut (Table 5).

Table 5 Variation of geometric parameters with pulse-OFF time

\begin{tabular}{lccc}
\hline Pulse-OFF time TFF $_{\text {OF }}(\mu \mathrm{s})$ & Theta (degrees) & Volume $\left(\mathrm{mm}^{3}\right)$ & Overcut $(\mathrm{mm})$ \\
\hline 1.8 & 11.8697 & 0.0497 & 0.1184 \\
3.8 & 8.0186 & 0.0351 & 0.0843 \\
5.8 & 6.3746 & 0.029 & 0.0692 \\
7.8 & 5.356 & 0.0255 & 0.0604 \\
9.8 & 4.6677 & 0.0232 & 0.0544 \\
\hline
\end{tabular}

Figure 8(a) shows that overcut decreases with increase in pulse-OFF time. This is because as pulse-OFF time increases, more time is available for electrolyte replenishment and heat dissipation. Therefore, electrolyte is more stabilised resulting in reduction in taper angle and hence overcut as well as MRR [Figure 8(b)].

Figure 8 (a) Overcut vs. pulse-off time (b) MRR vs. pulse-OFF time (see online version for colours)

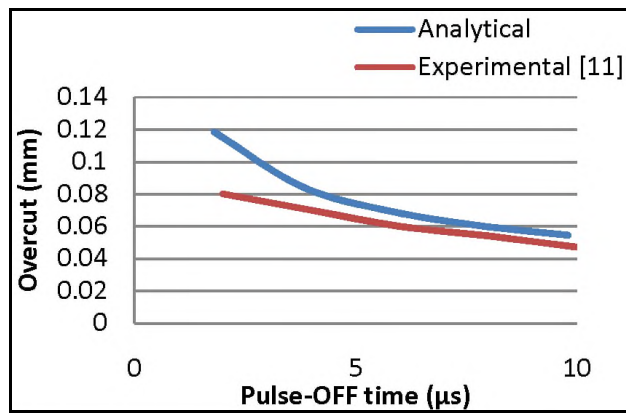

(a)

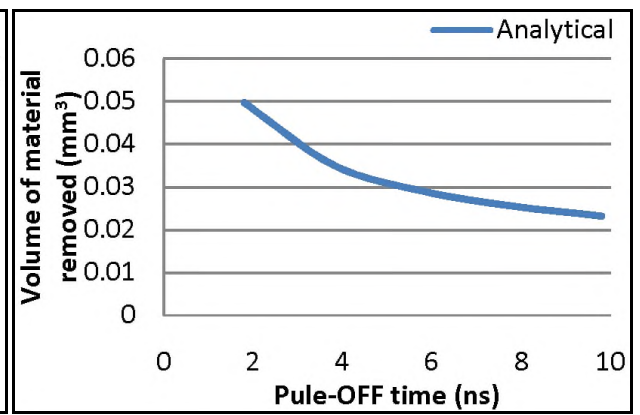

(b) 
Comparing the results with those in the literature (Shin et al., 2008), it is observed that analytical model over-predicts the results in all cases. This is because model assumes constant conductivity and no void (bubble) formation resulting in, supposedly, more supply of energy than the energy actually available in practice for material removal.

\subsection{Conical and hemispherical tools}

Similar studies (as in Section 2.3) are carried out for conical and hemispherical bottom tool shapes and trends in the results were studied. It was observed that trends for process parameters were similar in both the cases. As a result, typical results for conical and hemispherical bottom tools are presented here.

\subsubsection{Conical tool}

The conical tool with half cone angle of 300 and axial height of $0.5 \mathrm{~mm}$ was chosen for study. Tool geometry along with the process parameters (Table 6) is given as input to the model and the parametric studies are carried out.

Table 6 Parameters used for study of conical tool

\begin{tabular}{lc}
\hline Parameters & Value \\
\hline Half cone angle & $30^{\circ}$ \\
Depth of hole to be machined & $0.5 \mathrm{~mm}$ \\
Applied voltage & $5 \mathrm{~V}$ \\
Electrical conductivity of electrolyte $[\mathrm{K}]$ & $0.04 \mathrm{mS} / \mathrm{cm}$ \\
Machinability coefficient $\left[\mathrm{K}_{\mathrm{v}}\right]$ & $0.2 \mathrm{~mm} / \mathrm{min}$ \\
Feed rate & $1 \mathrm{gm} / \mathrm{s}$ \\
Pulse-ON time & $200 \mathrm{~ns}$ \\
Pulse time & $2 \mathrm{gs}$ \\
\hline
\end{tabular}

Figure 9(a) shows 2D work profile generated by model for conical tool with half cone angle of 300. 3D representation for the same is given by Figure 9(b).

\subsubsection{Hemispherical bottom tool}

The hemispherical bottom tool with radius $0.2 \mathrm{~mm}$ is chosen for study. Tool geometry along with the process parameters (mentioned in Table 7) is given as input to the model and the parametric studies are carried out.

Figure 10(a) shows 2D work profile generated by model for hemispherical bottom tool with radius $0.2 \mathrm{~mm}$, whereas $3 \mathrm{D}$ representation for the same is given by Figure 10(b).

All parametric studies for conical and hemispherical bottom tool show same trends as observed for cylindrical tool (Shah, 2015). It was seen that for conical and hemispherical tools, taper angle and MRR increases with increase in applied voltage and pulse-ON time, whereas decreases with increase in feed rate and pulse-OFF time. 
Figure 9 (a) $2 \mathrm{D}$ tool and work profile for conical tool (half cone angle $=30^{\circ}$ ) (b) $3 \mathrm{D}$ tool (centre) and work profile (outside) for conical tool (see online version for colours)

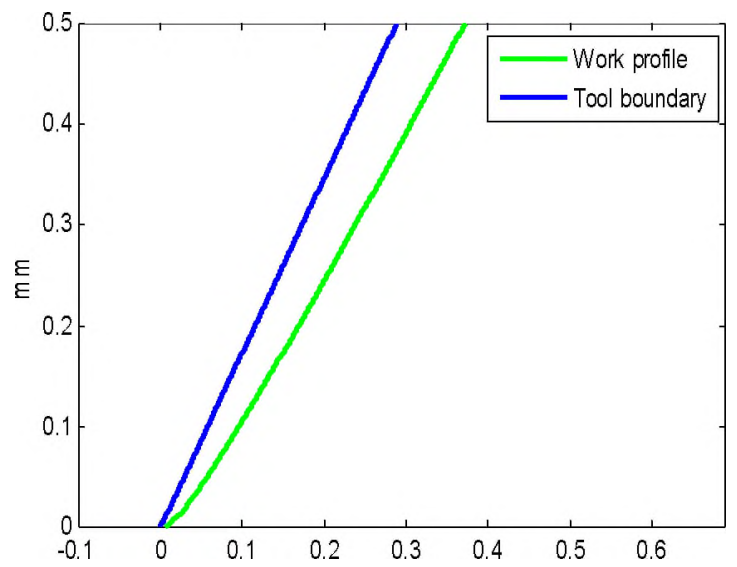

(a)

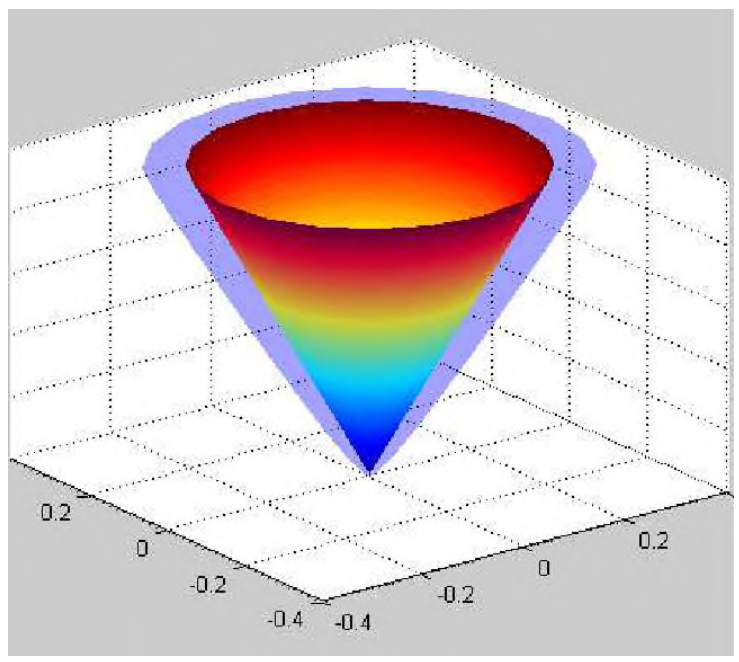

(b)

Table 7 Parameters used for study of hemispherical bottom tool

\begin{tabular}{lc}
\hline Parameters & Value \\
\hline Radius of hemispherical portion & $0.2 \mathrm{~mm}$ \\
Depth of hole to be machined & $0.7 \mathrm{~mm}$ \\
Applied voltage & $5 \mathrm{~V}$ \\
Electrical conductivity of electrolyte $[\mathrm{K}]$ & $0.04 \mathrm{mS} / \mathrm{cm}$ \\
Machinability coefficient $\left[\mathrm{K}_{\mathrm{v}}\right]$ & $0.2 \mathrm{~mm} / \mathrm{min}$ \\
Feed rate & $1 \mathrm{gm} / \mathrm{s}$ \\
Pulse-ON time & $200 \mathrm{~ns}$ \\
Pulse time & $2 \mathrm{gs}$ \\
\hline
\end{tabular}


Figure 10 (a) 2D tool and work profile for hemispherical bottom tool (b) 3D tool and work profile for hemispherical bottom tool (see online version for colours)

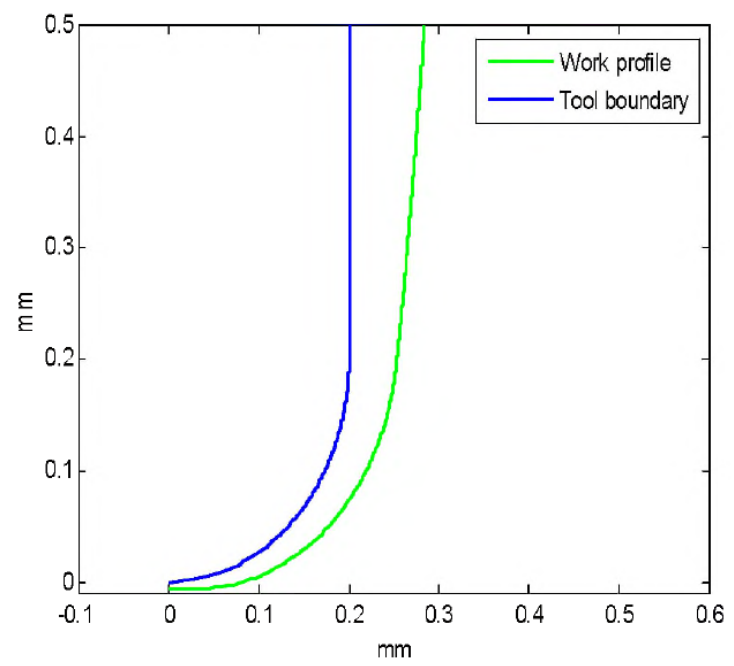

(a)

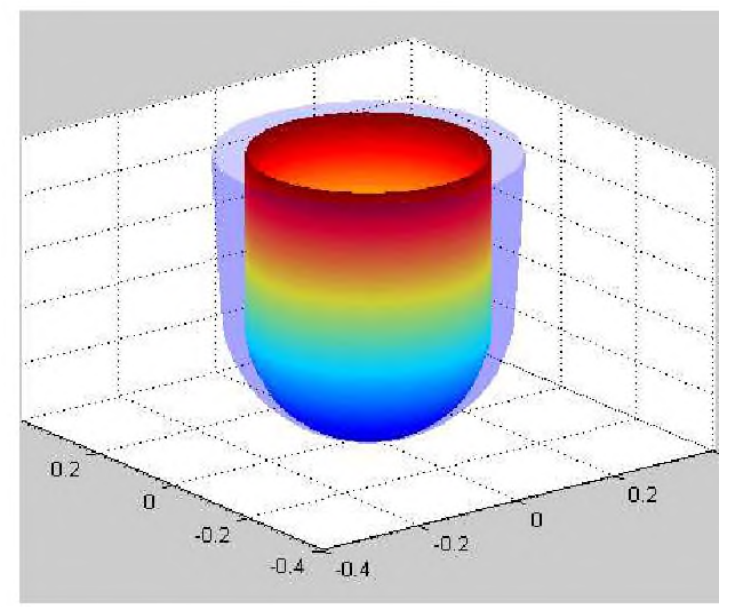

(b)

\subsection{Tool profile correction}

The mathematical model developed in Section 2.2 can be used in an inverse manner to predict and correct the tool shape which in turn, would generate the work profile. The key idea behind the algorithm remains the same which is calculation of IEG at each node. Required work shape is given as input to the model along with geometric and process parameters. The work boundary is descretised into number of nodes in such a way that distance between two nodes is the distance travelled by tool in one pulse time. The time of contact for each node is calculated and for that time, the node is displaced radially 
inwards by taking into consideration modified IEG and the current density variation to find out total displacement at each node. All the displaced nodes on tool boundary are joined together to obtain the final tool profile which will in turn, produce required work profile.

Using the above logic, model is developed and implemented in MATLAB to get tool profile for given work shape. Cylindrical work cavity is taken as a case study for tool profile prediction. Table 8 shows geometric and process parameters used for the case study.

Figure 11(a) shows 2D tool profile which will supposedly produce cylindrical cavity of $0.2 \mathrm{~mm}$ diameter, whereas 3D representation for the same is given by Figure 11(b).

Figure 11 (a) 2D cross-section of tool and work profile for cylindrical cavity (b) 3D tool (centre) and work profile (outside) (see online version for colours)

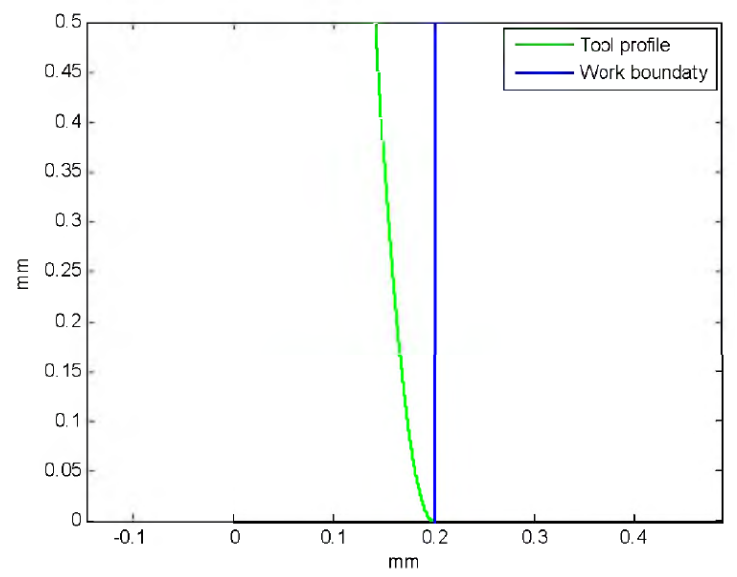

(a)

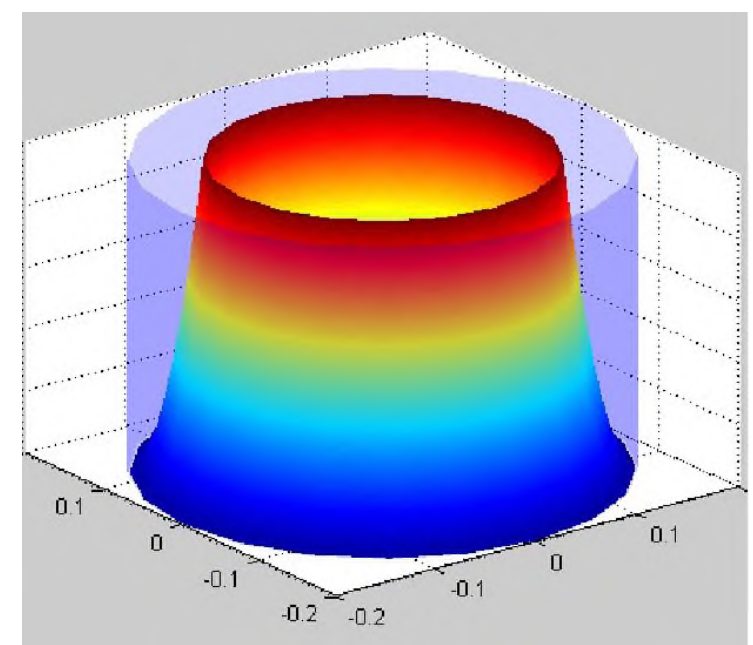

(b) 
Table 8 Parameters used for study of cylindrical cavity generation

\begin{tabular}{lc}
\hline Parameters & Value \\
\hline Radius of hole to be machined & $0.5 \mathrm{~mm}$ \\
Depth of hole to be machined & $0.2 \mathrm{~mm}$ \\
Applied voltage & $10 \mathrm{~V}$ \\
Electrical conductivity of electrolyte $[\mathrm{K}]$ & $0.04 \mathrm{mS} / \mathrm{cm}$ \\
Machinability coefficient $\left[\mathrm{K}_{\mathrm{v}}\right]$ & $0.2 \mathrm{~mm}^{3} / \mathrm{min}$ \\
Feed rate & $10 \mu \mathrm{m} / \mathrm{s}$ \\
Pulse-ON time & $500 \mathrm{~ns}$ \\
Pulse time & $2 \mu \mathrm{s}$ \\
\hline
\end{tabular}

This model can be implemented to find out predicted tool profile for any shape of work profile. Needless to say that these are ideal profile corrections and predictions which will get modified in actual conditions due to inadequacy of model.

\section{Experimental studies}

\subsection{Micro-ECM setup}

Figure 12 shows the experimental setup of micro-ECM developed at IIT Bombay. It consist of 3-axis feed mechanism with a resolution of $0.1 \mu \mathrm{m}$ along each axis with a minimum feed of $0.1 \mu \mathrm{m} / \mathrm{s}$, DC power supply ranging from $0-60 \mathrm{~V}$ with constant voltage mode facility, electrode holder system and electrolyte circulation system. The micro-tools of required dimensions are prepared on micro-turning facility available on multifunctional hybrid-EDM machine (Shah, 2015).

Figure 12 Experimental setup for micro-ECM (see online version for colours)

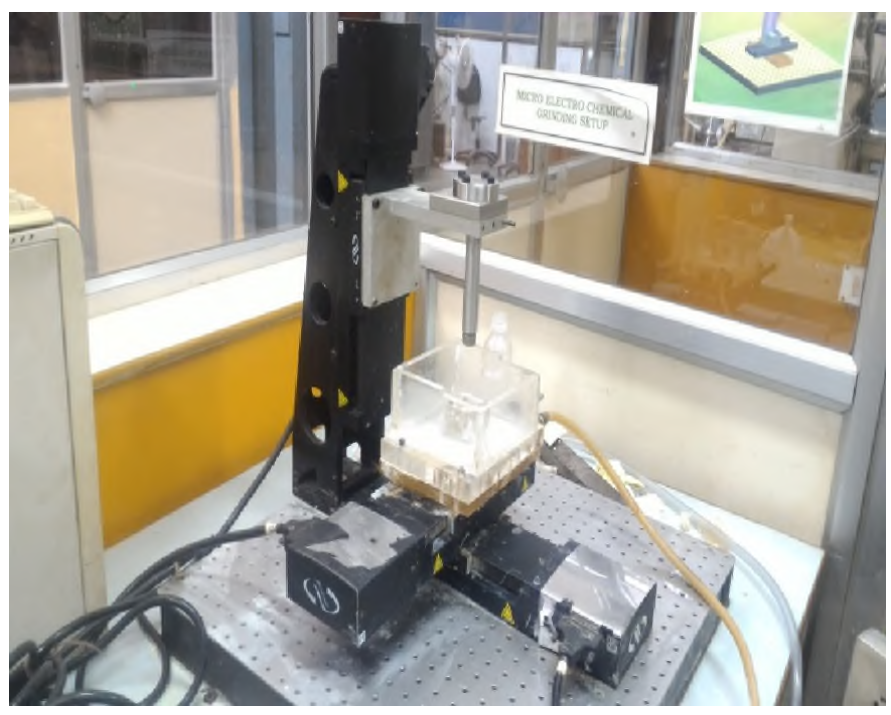




\subsection{Case studies - cylindrical tool}

Cylindrical tool of $550 \mu \mathrm{m}$ diameter was chosen and parameters in Table 9 were chosen for study. Out of several machined holes, six typical cases are considered here to validate the model and to study effect of voltage and feed rate.

Table 9 Machining conditions for microhole fabrication

\begin{tabular}{lc}
\hline Tool & $\Phi 550 \mu \mathrm{m}$ (copper) \\
Workpiece & $40 \times 20 \times 3 \mathrm{~mm}(\mathrm{SS}-304)$ \\
Electrolyte concentration & $15 \mathrm{gm} / \mathrm{ltr} \mathrm{NaOH}$ \\
Applied voltage & $8,10,12 \mathrm{~V}$ \\
Feed rate & $0.3,0.6,0.7,0.8 \mu \mathrm{m} / \mathrm{s}$ \\
\hline
\end{tabular}

Figure 13 shows experimentally obtained typical profile of the hole using Zeta profilometer (Shah, 2015). Profile predicted by the model is overlapped on experimentally obtained profile (in window).

Figure 13 Hole profile from experimentation (see online version for colours)

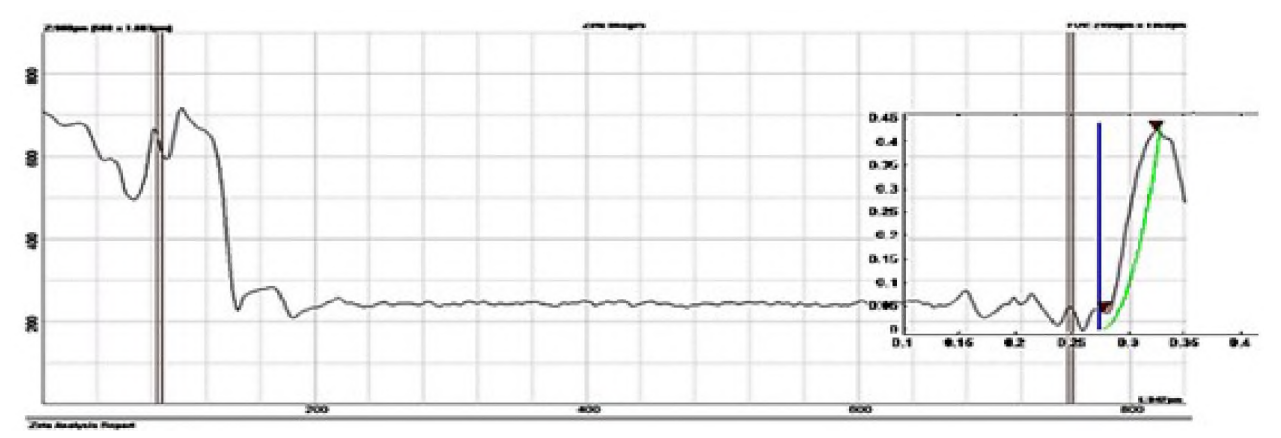

Note: $V=8 \mathrm{~V}, f=0.6 \mu \mathrm{m} / \mathrm{s}$.

Table 10 shows comparison between experimental and analytical results for the six cases under consideration. The comparison of profiles is carried out in terms of Taper angle and overcut. In all cases, model is seen to overpredict the results by about $20 \%-25 \%$. The probable reasons for this could be the simplifications in the model. The values of taper angle and overcut predicted by the model are however reasonably realistic. Effect of voltage and feed rate on the accuracy of the profile produced is studied.

\subsubsection{Effect of applied voltage}

Holes 1, 2 and 3 from the case studies are obtained by changing applied voltage at constant feed rate $(0.6 \mu \mathrm{m} / \mathrm{s})$. The results are summarised in Table 11 .

It is observed from Figure 14 that taper angle and hence overcut increases monotonically with increase in applied voltage. This is because the increase in voltage increases energy which results in more dissolution. 
Table 10 Analytical and experimental results of case studies

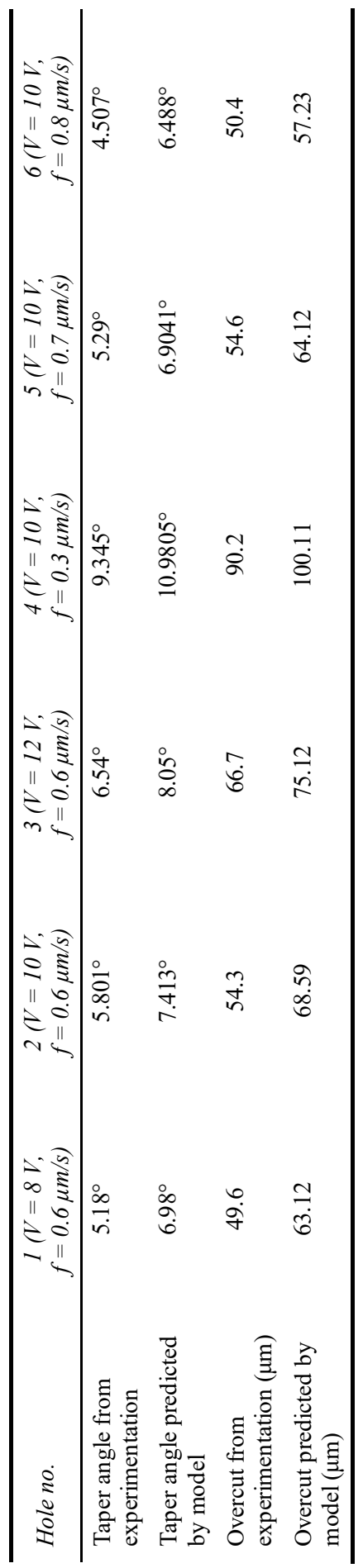


Table 11 Variation of taper angle with applied voltage

\begin{tabular}{lccc}
\hline Hole no. & Voltage $(V)$ & Experimental (degrees) & Model predicted (degrees) \\
\hline 1 & 8 & 5.18 & 6.98 \\
2 & 10 & 5.801 & 7.413 \\
3 & 12 & 6.54 & 8.05 \\
\hline
\end{tabular}

Figure 14 Taper angle vs. applied voltage at constant feed rate (see online version for colours)

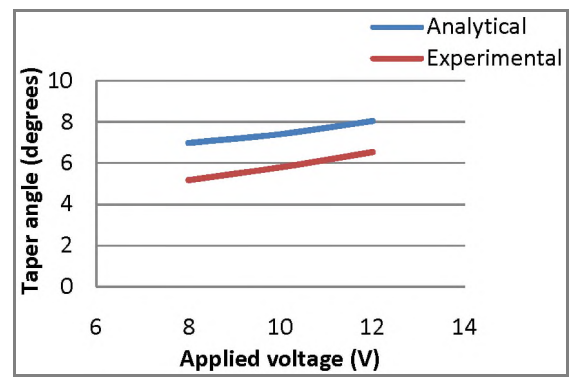

Note: $f=0.6 \mu \mathrm{m} / \mathrm{s}$.

\subsubsection{Effect of feed rate}

Holes 2, 4, 5 and 6 from the case studies are obtained by changing applied voltage at constant voltage $(10 \mathrm{~V})$. The results are summarised in Table 12.

Table 12 Variation of taper angle with feed rate

\begin{tabular}{lccc}
\hline Hole no. & Feed rate $(\mu \mathrm{m} / \mathrm{s})$ & Experimental (degrees) & Model predicted (degrees) \\
\hline 2 & 0.3 & 9.345 & 10.9805 \\
4 & 0.6 & 5.801 & 7.413 \\
5 & 0.7 & 5.29 & 6.9041 \\
6 & 0.8 & 4.507 & 6.488 \\
\hline
\end{tabular}

Note: $V=10 \mathrm{~V}$.

It is observed from Figure 15 that taper angle and hence overcut decreases monotonically with increase in the feed rate. This is due to reduction in time of contact with increase in feed rate.

Figure 15 Taper angle vs. feed rate at constant applied voltage

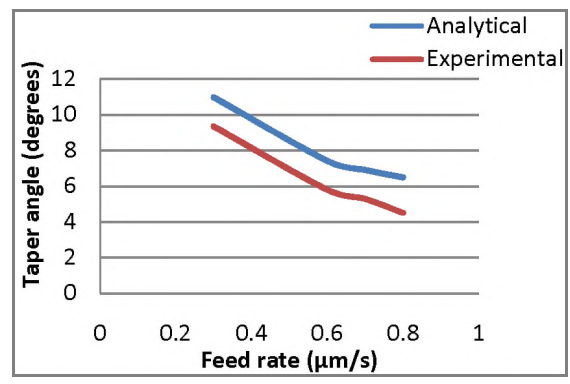


In both cases, it is observed that model over-predicts the results. However, the trends shown by analytical and experimental results are matching. This is because model assumes constant conductivity, no void (bubble) formation in IEG and neglect of thermal effects resulting in supposedly more supply of energy than the energy actually available in practice for material removal.

\section{Conclusions}

This paper reported the development of analytical model for micro-ECM process to predict profile shape of workpiece internal features for various tool shapes (cylindrical, conical and hemispherical) and process conditions. The developed system was extensively tested with inhouse experimental case studies for cylindrical tool shape as well as with the results available in the literature. It was found to predict workpiece internal profile with reasonable accuracy. Further work on the process model needs to be done to improve its prediction accuracy. The predicted work profile can be used to correct the tool profile in an inverse manner to improve process accuracy. Parametric studies show that low voltage, high feed rate, small pulse-ON time and large pulse-OFF time should be simultaneously adapted for better profile reproduction.

\section{References}

Ahn, S.H. et al. (2004) 'Electro-chemical micro drilling using ultra short pulses', Precision Engineering, Vol. 28, No. 2, pp.129-134.

Bhattacharyya, B., Mitra, S. and Boro, A.K. (2002) 'Electrochemical machining: new possibilities for micromachining', Robotics and Computer-Integrated Manufacturing, Vol. 18, No. 3, pp.283-289.

Ghoshal, B. and Bhattacharyya, B. (2015) 'Investigation on profile of microchannel generated by electrochemical micromachining', Journal of Materials Processing Technology, August, Vol. 222, pp.410-421, https://doi.org/10.1016/j.jmatprotec.2015.03.025.

Jo, C.H., Kim, B.H. and Chu, C.N. (2009) 'Micro electrochemical machining for complex internal micro features', CIRP Annals-Manufacturing Technology, Vol. 58, No. 1, pp.181-184.

Kim, B.H. et al. (2005) 'Micro electrochemical machining of 3D micro structure using dilute sulfuric acid', CIRP Annals - Manufacturing Technology, Vol. 54, No. 1, pp.191-194.

Kozak, J., Budzynski, A.F. and Domanowski, P. (1998) 'Computer simulation electrochemical shaping (ECM-CNC) using a universal tool electrode', Journal of Materials Processing Technology, Vol. 76, No. 1, pp.161-164.

Kozak, J., Gulbinowicz, D. and Gulbinowicz, Z. (2008) 'The mathematical modeling and computer simulation of pulse electrochemical micromachining', Engineering Letters, Vol. 16, No. 4, pp.556-561.

Mathew, R. and Sundaram, M.M. (2012) 'Modeling and fabrication of micro tools by pulsed electrochemical machining', Journal of Materials Processing Technology, Vol. 212, No. 7, pp.1567-1572.

Mi, D., Nomura, H. and Natsu, W. (2015) 'Original article proposal of ECM method for holes with complex internal features by controlling conductive area ratio along tool electrode', Precision Engineering, October, Vol. 42, pp.179-186, https://doi.org/10.1016/j.precisioneng.2015.04.015. 
Mithu, M.A.H. et al. (2012) 'On how tool geometry, applied frequency and machining parameters influence electrochemical microdrilling', CIRP Journal of Manufacturing Science and Technology, Vol. 5, No. 3, pp.202-213.

Prentice, G.A. and Tobias, C.W. (1982) 'Simulation of changing electrode profiles', Journal of the Electrochemical Society, Vol. 129, No. 1, pp.78-85.

Rajurkar, K.P., Sundaram, M.M. and Malshe, A.P. (2013) 'Review of electrochemical and electrodischarge machining', Procedia CIRP, Vol. 6, pp.13-26, https://doi.org/10.1016/j.procir.2013.03.002.

Shah, P. (2015) Computer Aided Tool Design for Micro-ECM, M.Tech Thesis, IIT Bombay.

Shin, H.S., Kim, B.H. and Chu, C.N. (2008) 'Analysis of the side gap resulting from micro electrochemical machining with a tungsten wire and ultrashort voltage pulses', Journal of Micromechanics and Microengineering, Vol. 18, No. 7, p.075009. 